\title{
Comparative Study of PMSG Controllers for Variable Wind Turbine Power Optimization
}

\author{
Asma Hammami, Imen Saidi, Dhaou Soudani \\ Automatic Research Laboratory, LA.R.A, National Engineering School of Tunis, ENIT \\ University of Tunis El Manar \\ Tunis, Tunisia
}

\begin{abstract}
With a large increase in wind power generation, the direct driven Permanent Magnet Synchronous Generator is the most promising technology for variable speed operation and it also fulfills the grid requirements with high efficiency. This paper studies and compares conventional based on PI controller and proposed control technique for a direct driven PMSG wind turbine. The generator model is established in the Park synchronous rotating $d-q$ reference frame. To achieve maximum power capture, the aeroturbine is controlled through Maximum Power Point Tracking (MPPT) while the PMSG control is treated through field orientation where the two currents control loops are regulated. A proposed direct-current based d-q vector control design is designed by the integration of the Internal Model Controller. Then an optimal control is developed for integrated control of PMSG power optimization and Voltage Source Converter control. The design system was done using SimWindFarm Matlab/Simulink toolbox to evaluate the performance of conventional and proposed technique control of PMSG wind turbine. The analysis, simulation results prove the effectiveness and robustness of the proposed control strategy.
\end{abstract}

Keywords-Wind turbine; internal model control; PI controller Permanent Magnet Synchronous Generator (PMSG); vector control

\section{INTRODUCTION}

Recently, wind energy system has been treated as an important renewable energy source which had higher potential to generate power where grids are not feasible. The wind generation systems have gained tremendous attention over fossil fuel and nuclear power generation due to the high cost and environmental clean [1]. At present the variable speed wind turbine is considered the most attractive solution to distribute power generation systems. Mainly four types of generators are used in wind power system: Squirrel cage induction generator - double fed induction generator - wound rotor synchronous generator - permanent magnet synchronous generator (PMSG). Considerable research has been devoted to the choice of PMSG for variable speed generation system. It has high efficiency, is connected directly to the turbine without gearbox and has full controllability of the system for maximum wind power extraction [2].

However, the performance of PMSG depends on the control strategy. Traditionally, PMSG with full scale PWM converter is controlled through the conventional decoupled d-q vector control. The overall problem that occurs in this method is the calculation for determination of controller parameters and the robustness performance. Most studies have used the adaptive control scheme as a robust method of control strategy while others use the artificial intelligence techniques. These structures are required for exact mathematical identification of controller parameters.

The Internal Model Control method was observed by Gracia and Morari [3], [4], and was later improved under intensive research and development. This design provides high performance dynamic characteristics. This structure covers an internal model of the plant and an internal model controller. In order to improve the disturbance rejection, a modified IMC is designed with an additional filter [5]. It provides good abilities of control system performance particularity for the stability and robustness issues.

This paper proposes a comparative study between conventional vector control with PI action controller and proposed IMC controller design applied for the purpose of improving the control effectiveness and overall performance of PMSG system.

This paper is structured as follows: In section 2 a mathematical model of the wind turbine with PMSG system is described. Section 3 deals with the PMSG control including the IMC proposed control is developed in section 4. The designed and traditional controls are compared and the validation results using SimWindFarm Matlab/Simulink toolbox are shown in section 5 .

\section{WIND TURBINE MODELING}

\section{A. Aeroturbine Modeling}

The aerodynamic blades allow the conversion of the kinetic energy of the wind profile into mechanical energy to the generator.

Therefore the aerodynamic torque $T_{a}$ is given by [6]:

$T_{a}=\frac{1}{2 \omega_{r}} \rho A V_{w}^{3} C_{p}(\lambda, \beta)$

Where $\rho$ is the air density, $A$ is the surface, $V_{w}$ is the wind speed. Each wind turbine is defined by its own power coefficient which is a nonlinear function depends on the pitch angle $\beta$ and the tip speed ratio $\lambda$.

The power coefficient can be represented as [6]: 
$\mathrm{C}_{\mathrm{p}}(\lambda, \beta)=\mathrm{c}_{1}\left(\frac{\mathrm{c}_{2}}{\lambda_{\mathrm{i}}}-\mathrm{c}_{3} \beta-\mathrm{c}_{4}\right) \mathrm{e}^{\frac{-\mathrm{c}_{5}}{\lambda_{\mathrm{i}}}}+\mathrm{c}_{6} \lambda$

$\frac{1}{\lambda_{\mathrm{i}}}=\frac{1}{\lambda+0.08 \beta}-\frac{0.035}{\beta^{3}+1}$

Where $\lambda=\frac{\omega_{r} R}{V_{w}}$ and $\mathrm{c}_{1}=0.5176 ; \mathrm{c}_{2}=116 ; \mathrm{c}_{3}=0.4$; $\mathrm{c}_{4}=5 ; \mathrm{c}_{5}=21 ; \mathrm{c}_{6}=0.0068$

The model of the dynamic wind turbine drive-train system assumed in several papers [1], [5], [6] is modeled through two mass drive-train system where the low shaft speed is the result of the torsion and friction effects. In order to reduce the model of the system and have a simple structure, the wind turbine is modeled as one mass drive-train system by conceding that the low shaft speed is quite rigid. Fig. 1 shows the reduced single mass drive-train model.

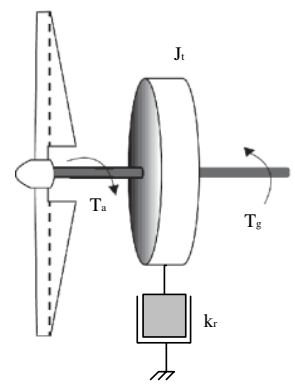

Fig. 1. One Mass Drive-Train Model.

The dynamic characterized by first order equation can be expressed as:

$\dot{\omega}_{r}=\frac{T_{a}}{J_{t}}-\frac{T_{e m}}{J_{t}}$

Where $J_{t}$ is the inertia, $\omega_{r}$ is the rotor speed and $T_{e m}$ is the electromagnetic generator torque.

\section{B. Permanent Magnet Synchronous Generator Modeling}

The mathematical model of permanent synchronous generator is developed in the Park $d-q$ rotation frame linked to the rotor [5].

$\left\{\begin{array}{l}v_{d}=R_{s} i_{d}+L_{d} \frac{d i_{d}}{d t}-L_{q} i_{q} \omega_{e} \\ v_{q}=R_{s} i_{q}+L_{q} \frac{d i_{q}}{d t}+L_{d} i_{d} \omega_{e}+\omega_{e} \phi\end{array}\right.$

Where $v_{d}$ and $v_{q}$ are the voltages, $i_{d}$ and $i_{q}$ are the currents along the $\mathrm{d}$ and $\mathrm{q}$ axis respectively, $R_{s}$ is the stator resistance, $L_{d}=L_{q}$ are the inductance of the generator, $\phi$ is the permanent magnetic flux, $\omega_{m}=\frac{\omega_{e}}{p}$ is the electrical rotating speed of the generator in which $p$ is the number of pole pairs. The electromagnetic torque equation can be written as follows
$T_{e m}=\frac{3}{2} p\left[\left(L_{d}-L_{q}\right) i_{d} i_{q}+i_{q} \phi\right]$

The difference between the $\mathrm{d}$ and $\mathrm{q}$ mutual inductance tends to zero for a direct drive multiple PMSG [6]. Then the electromagnetic torque depends only on the q axis current. Eq. (5) can be reduced to Eq. (6):

$T_{e m}=\frac{3}{2} p i_{q} \phi$

\section{Converter Model}

The generator side converter (GSC) is a rectifier which is used to control the torque and speed. The three side converter connected to the output of PMSG is presented in Fig. 2.

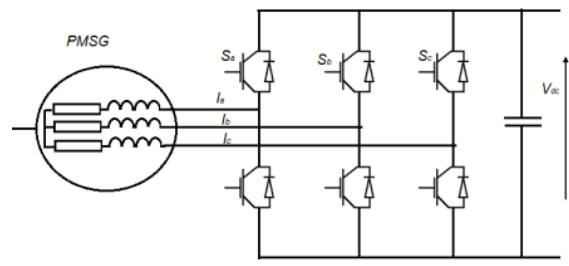

Fig. 2. PMSG with GSC.

According to Fig. 2 the three phase voltage is written as follows [7]:

$\left[\begin{array}{l}e_{a} \\ e_{b} \\ e_{c}\end{array}\right]=R\left[\begin{array}{l}i_{a} \\ i_{b} \\ i_{c}\end{array}\right]+L \frac{d}{d t}\left[\begin{array}{l}i_{a} \\ i_{b} \\ i_{c}\end{array}\right]+\left[\begin{array}{c}v_{a} \\ v_{b} \\ v_{c}\end{array}\right]$

Where $v_{a}, v_{b}$ and $v_{c}$ are the applied voltages at the machine terminals. They are given by the following equation:

$\left[\begin{array}{l}v_{\mathrm{a}} \\ v_{\mathrm{b}} \\ v_{\mathrm{c}}\end{array}\right]=\frac{1}{3} v_{\mathrm{dc}}\left[\begin{array}{ccr}2 & -1 & -1 \\ -1 & 2 & -1 \\ -1 & -1 & 2\end{array}\right]\left[\begin{array}{l}S_{\mathrm{a}} \\ S_{\mathrm{b}} \\ S_{\mathrm{c}}\end{array}\right]$

Where $S_{\mathrm{a}}, S_{\mathrm{b}}, S_{\mathrm{c}}$ are the switching variables of the converter, $v_{\mathrm{dc}}$ is the DC link voltage.

\section{Control Objectives}

The objective of the wind turbine control is the tracking of the optimal speed reference that guarantees the optimization of the wind power capture. So the power coefficient must be maintained at its maximum value $C_{p \max }$ which is obtained at an optimal tip-speed ratio $\lambda_{\text {opt }}$ and a specific pitch angle with $\lambda_{\text {opt }}=\frac{\omega_{\text {opt }} R}{V}$ that $\omega_{\text {opt }}$ is the optimal rotational speed.

If the conditions optimal are required, the maximum power output is given through [6]:

$P^{o p t}=\frac{1}{2} \rho \pi S C_{p \max } \frac{\omega_{o p t}{ }^{3} R^{3}}{\lambda_{o p t}{ }^{3}}$ 
However, MPPT control is ensured by maintaining the optimal relation between the generator's speed and the torque without using wind speed measurement. From the optimum power given by Eq. (9) the optimum generator torque can be written as follows:

$$
T_{o p t}=K_{o p t} \omega_{o p t}^{2}
$$

Where

$$
K_{o p t}=\frac{1}{2} \rho \pi R^{5} \frac{C_{p \max }}{\lambda_{o p t}{ }^{3}}
$$

The main objective of the PMSG controller is the tracking aeroturbine input which is the electromagnetic reference torque.

\section{PMSG CONTROL DESIGN}

The mostly often used control approach of PMSG known as field oriented control (FOC) presents several advantages such as accurate speed control and good torque response achieved through the $d-q$ current control loop. This control consists in ensuring that the $q$ axis current measured $i_{q}$ trackes the $q$ axis current reference $i_{q}^{*}$ and that the $d$ axis current measured $i_{d}$ reaches the $d$ axis current reference $i_{d}^{*}$ [7], [8], [9].

In order to produce maximum torque, the $\mathrm{d}$ axis stator current is maintained at zero. The developed torque is proportional to the q component of the stator current, so the $q$ axis stator reference current is calculated using the turbine MPPT unit. The overall structure of wind turbine-PMSG control strategy is shown in Fig. 3.

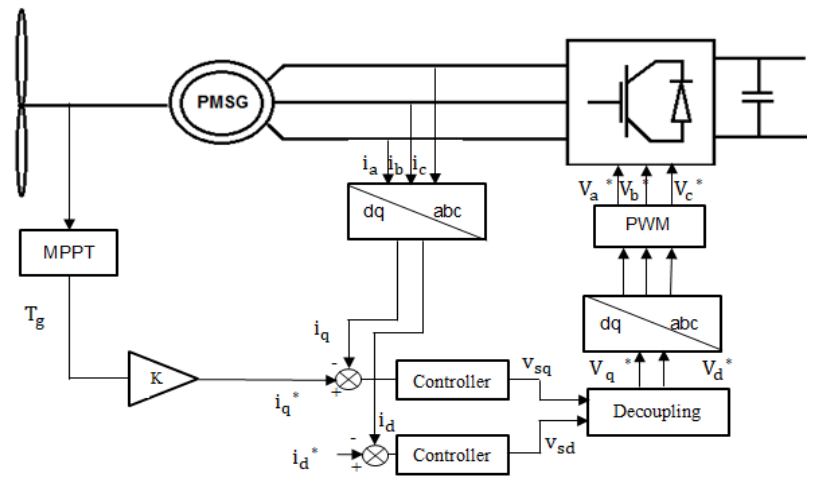

Fig. 3. Wind Turbine-PMSG Control.

The decoupled $d$ and $q$ current loops are expressed by the state equation between the voltage and current on $d$ and $q$ loops and the other components are considered as compensation items. Eq. (4) can be rewritten as:

$\left\{\begin{array}{l}v_{d}=v_{s d}-L_{q} i_{q} \omega_{e} \\ v_{q}=v_{s q}+L_{d} i_{d} \omega_{e}+\omega_{e} \phi\end{array}\right.$

\section{A. Proportional Integral Controller Synthesis}

The controller design of this approach is based on the system block diagram as drawn in Fig. 4. The same control structure loop is applied for the $d$ and $q$ axis current loop control. The transfer function between $i_{d, q}$ and $v_{d, q}$ is given by:

$$
\frac{I_{d, q}(\mathrm{~s})}{V_{d, q}(\mathrm{~s})}=\frac{1}{R_{s}} \frac{1}{1+T_{e} s}
$$

Where the stator time constant is $T_{e}=\frac{L_{d, q}}{R_{s}}$

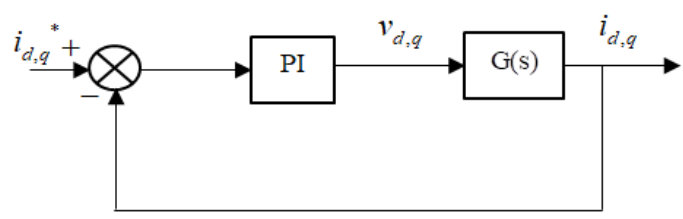

Fig. 4. Current Control Loop.

The Proportional Integral controller is defined as:

$C(\mathrm{~s})=\frac{k_{i}}{s}\left(1+\frac{k_{p}}{k_{i}} \mathrm{~s}\right)$

The parameters of the PI controller are determined through the open-loop pole compensation method as follows:

$\left\{\begin{array}{l}k_{i}=\frac{R_{s}{ }^{2}}{L_{d, q}} \\ k_{p}=\frac{L_{d, q} k_{i}}{R_{s}}\end{array}\right.$

The $\mathrm{d}$ and $\mathrm{q}$ axis voltages reference $v_{q}^{*}$ and $v_{d}^{*}$ are generated from the addition of the controllers output to the compensation items, from which the three phase sinusoidal reference voltage is obtained. Thus the control of the stator $d$ and $q$ currents is achieved through the decoupled $d$ and $q$ voltages. PWM is used to generate the switching signal for the power converter. The closed-loop control strategy for generator-side converter is shown as Fig. 3.

\section{B. Internal Model Controller}

The vector control of the synchronous generator in Fig. 3 shows that the generated d-q axis voltage is based on the error between the measured and the reference $d-q$ axis currents. The proposed method control of this paper is the use of IMC controller in place of PI controller.

The major advantages of the IMC structure are: the use of IMC controller feedback signal of the difference between the plant model and the reference model, the IMC controller equally ensures the robustness of the system [10].

The design control strategy of the system consists in controlling the $d-q$ stator current with two separate IMC controller loops. The generated $\mathrm{d}$ and $q$ current $i_{s d}$ and $i_{s q}$ from the outputs of the IMC controllers are then added to the compensation items in order to compute the $d-q$ reference voltage [14], [15]. The $v_{d}{ }^{*}$ and $v_{q}{ }^{*}$ are written as: 


$$
\left\{\begin{array}{l}
v_{d}^{*}=R_{s} i_{s d}-L_{q} i_{s q} \omega_{e} \\
v_{q}^{*}=R_{s} i_{s q}+L_{d} i_{s d} \omega_{e}+\omega_{e} \phi
\end{array}\right.
$$

After the transformation of the measured stator currents from three phase $a b c$ to $d q$ rotating frame, the IMC controllers system operate to minimize the difference between the reference and actual currents on $\mathrm{d}$ and $\mathrm{q}$ loops.

The IMC scheme block diagram is shown in Fig. 5.

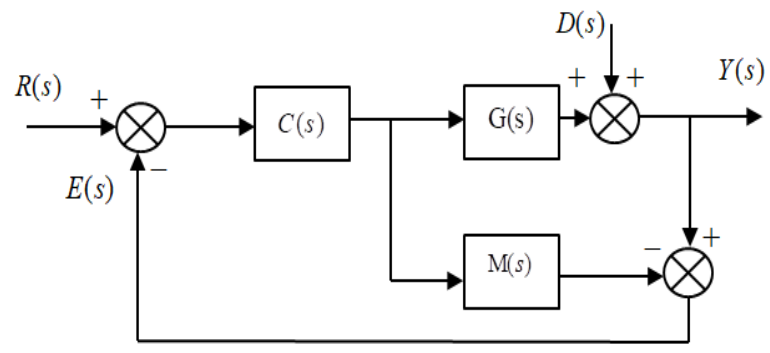

Fig. 5. Standard IMC Structure.

Where $G(s)$ is the mathematical model of the plant, $M(s)$ is the model, $C(s)$ is the model controller, $D(s)$ is the disturbance. $E(s)$ is the information of the disturbance and model plant mismatch as defined as Eq.(16).

$E(\mathrm{~s})=\frac{D(s)+\mathrm{R}(\mathrm{S}) \mathrm{C}(\mathrm{s})[\mathrm{G}(\mathrm{s})-M(\mathrm{~s})]}{1+\mathrm{C}(\mathrm{s})[\mathrm{G}(\mathrm{s})-M(\mathrm{~s})]}$

The IMC structure guarantees the stability of the system for the open loop stable plant. The internal model is perfect, $G(s)=M(s)$ and the closed-loop system is stable if $M(s), G(s)$ and $C(s)$ are stable [11]. Then, in an ideal internal model control is presented as $C(s)=M^{-1}(s)$. However it can be seen that the output of the system cannot reach an input of the system due to a number of reasons [12]:

a) If is not minimum phase, there are zeros in the right half plane, then is unstable.

b) There are some parts of the system which are noninvertible.

c) It is highly sensitive to model errors

In this case and by using the inversion method proposed in [11] which is based on the gain, we achieved an inverse model of the plant model. The IMC controller is given as follows as Fig. 6.

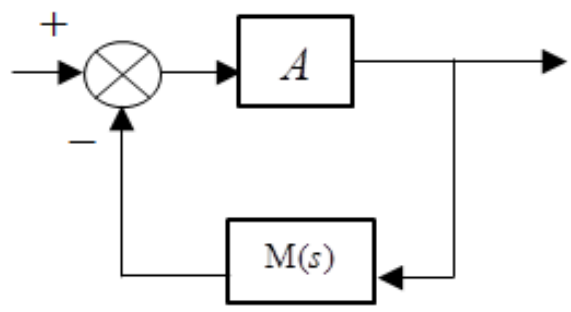

Fig. 6. IMC Controller Structure.
The expression of the internal model controller can be obtained as :

$$
C(s)=\frac{A}{1+A M(\mathrm{~s})}
$$

Referring to [11],[12],[13] to ensure the stability of the structure proposed, the choice of the gain $A$ must satisfy the condition that the roots of the characteristic equation have negative real parts. The IMC structure can be modified to get a standard feedback control system as shown in Fig. 7. This configuration is more straightforward for implementing the current control loops.

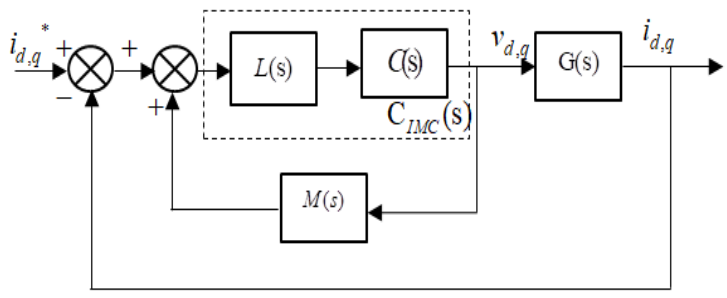

Fig. 7. Modified IMC Structure.

In order to make the system more robust, the controller is raised by a filter. The filter used is the low-pass filter which is given by [13].

$$
L(s)=\frac{1}{(1+\varepsilon s)^{n}}
$$

Where $\varepsilon$ is the time constant and $n$ is the order of the system.

The selection of the filter parameter must confirm an acceptable compromise between stability and performance. The adjusting of $\varepsilon$ is related to control the stator current of the closed loop response. The filter order should be chosen as appropriately in order to get the fast and robust required system. Then the IMC controller is defined as:

$C_{I M C}(s)=L(s) C(s)$

The plant of the IMC control block diagram is $G(s)=\frac{1}{L_{d, \mathrm{q}} s+R_{s}}$ which has strict negative real part root $p_{1}=-74.17$, the model is similar to the plant and the filter is taken in the first order.

Then, the expression of IMC controller is defined by:

$$
\mathrm{C}_{I M C}(s)=\frac{1.42910^{-6} s+1.0610^{-4}}{5.71610^{-4} s^{2}+5.66910^{-2} s+1.06}
$$

$\mathrm{C}_{\mathrm{IMC}}(\mathrm{s})$ is stable in open loop because the denumerator coefficients of his transfer function are all of the same sign.

\section{VALIDATION RESULTS}

The proposed PMSG controller was validated using the SimWindFarm aeroelastic simulator with the parameters of the NREL-5MW variable wind turbine. The NREL-5MW is a 
variable speed, variable pitch with a nominal power rating of $5 \mathrm{MW}$, a $126 \mathrm{~m}$ diametre, three blades. It is assumed to be coupled to a three-phase PMSG. The main parameters of the wind turbine and PMSG are summarized in Table I.

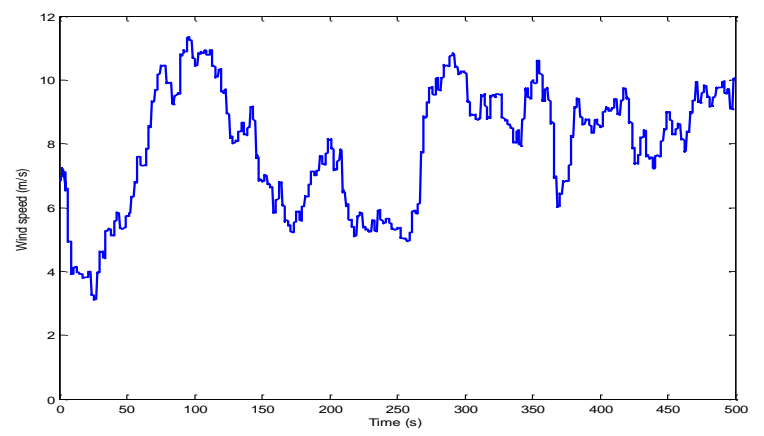

Fig. 8. Wind Speed Profile.

The wind profile used in this study is generated by the simulator. It has a mean value of $7 \mathrm{~m} . \mathrm{s}^{-1}$ at the hub-height and a turbulence intensity of $25 \%$ as shown in Fig. 8.

TABLE I. WT-PMSG CHARACTERISTICS

\begin{tabular}{|l|l|}
\hline Parameters & value \\
\hline Rotor diameter & $126 \mathrm{~m}$ \\
\hline Gearbox ratio & 97 \\
\hline Hub-height & $87.6 \mathrm{~m}$ \\
\hline Maximum power coef. & 0.482 \\
\hline Rated speed & $1173.7 \mathrm{rpm}$ \\
\hline Rated power & $5 \mathrm{MW}$ \\
\hline Maximum rotor torque & $47,402 \mathrm{~N} . \mathrm{m}$ \\
\hline Stator resistance & $1.06 \Omega$ \\
\hline Stator inductance & $14.29 \mathrm{mH}$ \\
\hline Rotor flux linkage & $8.6 \mathrm{~Wb}$ \\
\hline Number of pole pairs & 5 \\
\hline
\end{tabular}

\section{A. PMSG with IMC Controller Validation}

The performance of PMSG control through the designed IMC controller is first investigated. As seen in Fig. 9 the rotor speed is kept around of the optimal reference speed. It is proportioned to the increase of the waveforms of wind speed. The high performance of the controller design is can be seen with the IMC controller which tracks the reference value with reducing steady-state error. Fig. 10 shows the electromagnetic torque which reaches the desired reference value and achieves a good performance. The electrical power resulted is kept near to the aerodynamic power optimal as seen in Fig. 11 with a power coefficient around the constant desired value 0.482 , Fig. 12.

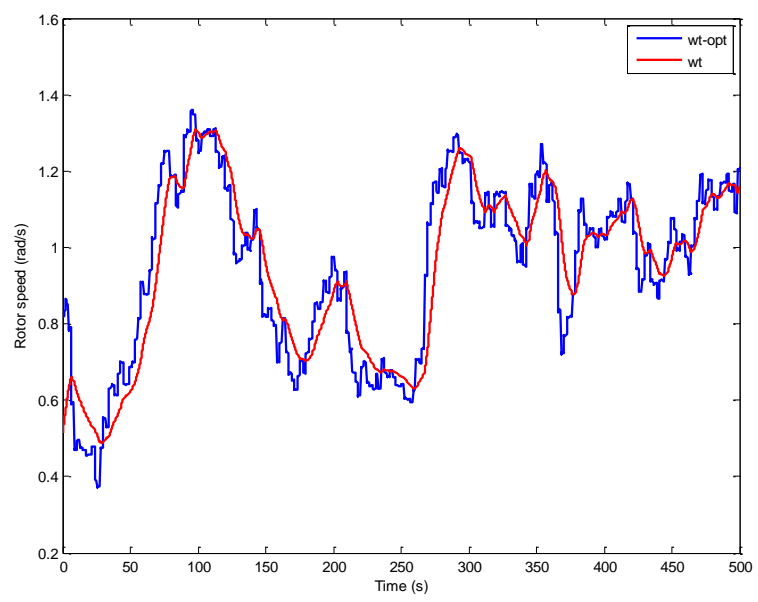

Fig. 9. Rotor Speed Response with IMC Controller.

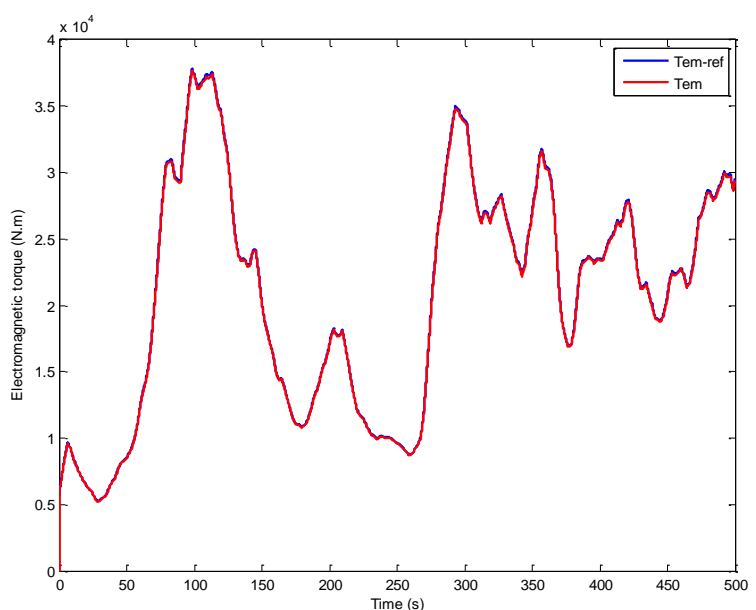

Fig. 10. Electromagnetic Torque with IMC Controller.

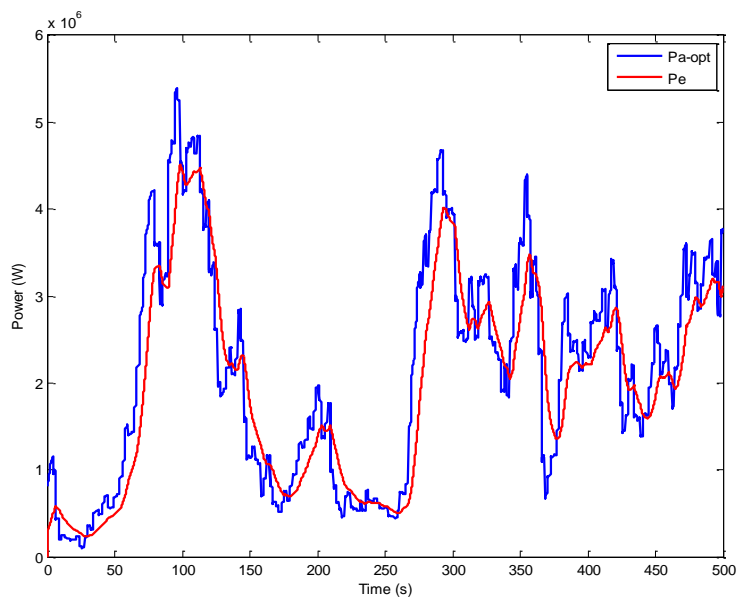

Fig. 11. Power with IMC Controller. 


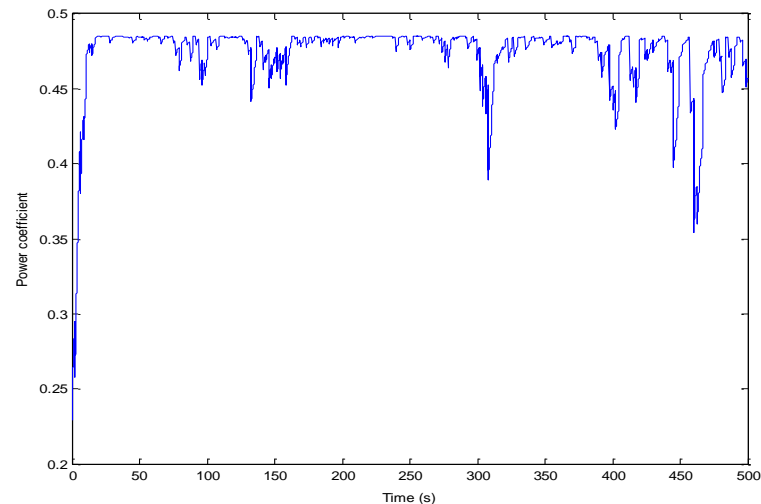

Fig. 12. Power Coefficient

Fig. 13 shows the $d q$-axis currents. The direct current component $i_{d}$ is close to zero, while the quadratic current component $i_{q}$ is directly related to the reference generator torque. As the desired electromagnetic torque increases so does the $q$-axis current. It is clearly that the active power is proportional to the quadratic current while the reactive power is only controlled by the direct current. The three-phase $a b c$ current as shown in Fig. 14 present a peak of $480 \mathrm{~A}$ at a rotor speed of $1.3 \mathrm{rad} / \mathrm{s}$. The three-phase voltage developed is presented in Fig. 15 which presents a peak around $6000 \mathrm{~V}$ at a rotor speed of $1.3 \mathrm{rad} / \mathrm{s}$. The electrical power delivered from the generator converter side shown in Fig. 16 is less than the one calculated through the torque generated. This decrease can be interpreted by the power losses through the converter and mechanical flexible elements.

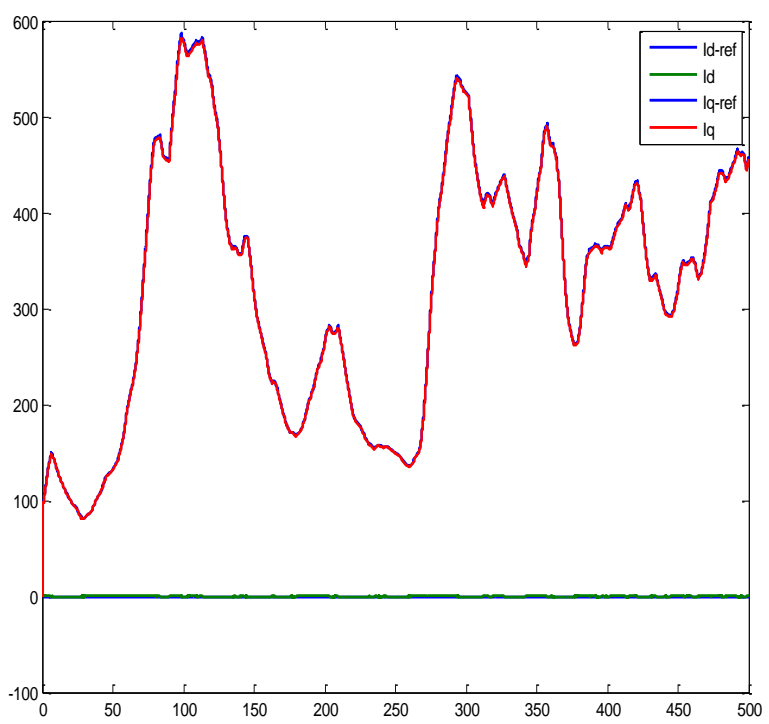

Fig. 13. Direct and Quadratic Current.

In order to test the robustness of the proposed IMC controller, the PMSG parameters $R_{s}$ and $L_{d, q}$ have been varied with $-20 \%$ of $L_{d, q}$ nominal value and $-50 \%$ of $R_{s}$ nominal value. Fig. 17 and 18 display simulation results for the parameters variation. It can be seen that the outputs system are able to reach the optimal reference value. So it is clear that the IMC controller has parameters incertitude robustness and it can be seen the effectiveness and the robustness of the designed controller.
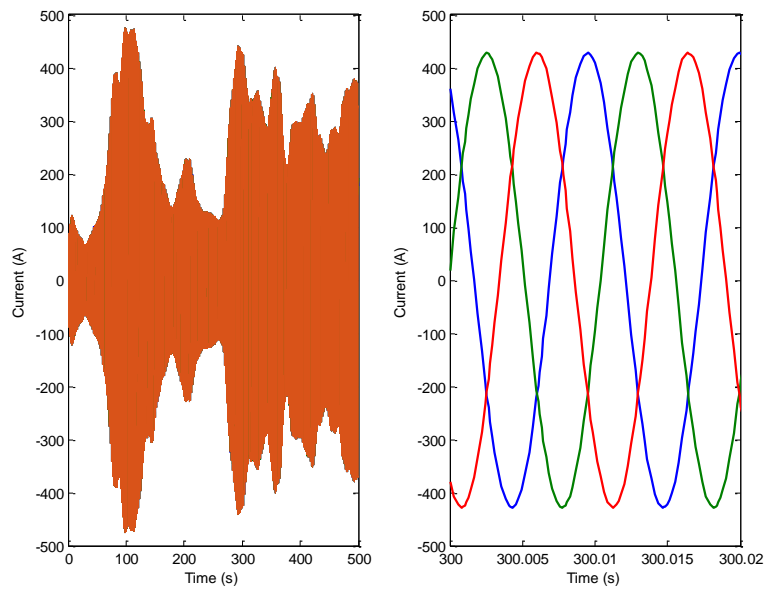

Fig. 14. Three-Phase abc Current.
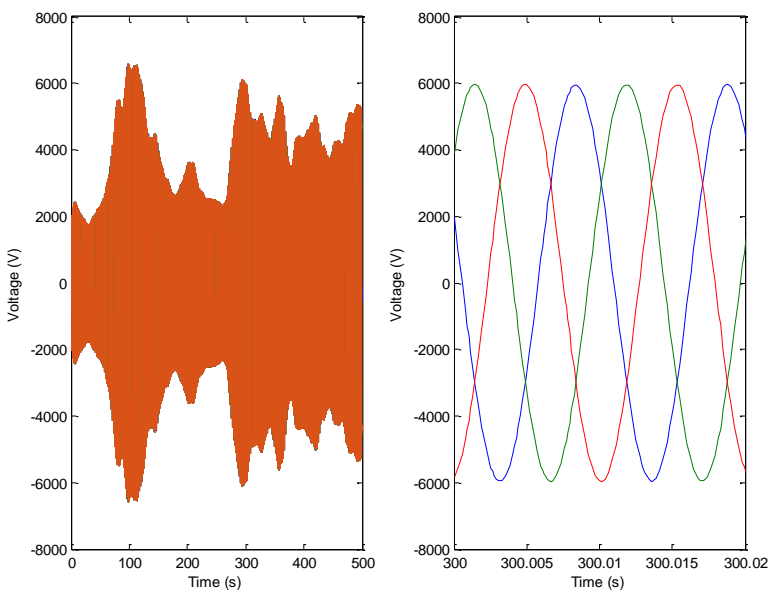

Fig. 15. Three-Phase abc Voltage.

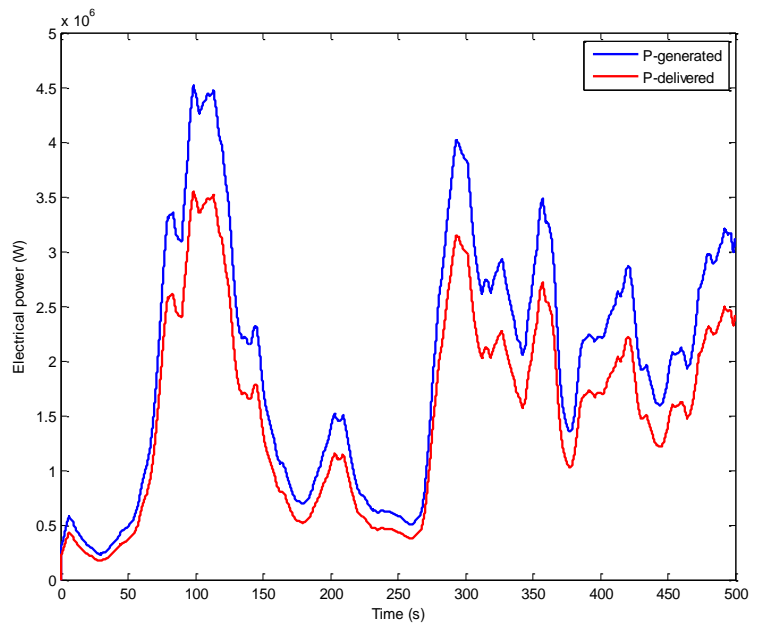

Fig. 16. Electrical Power. 


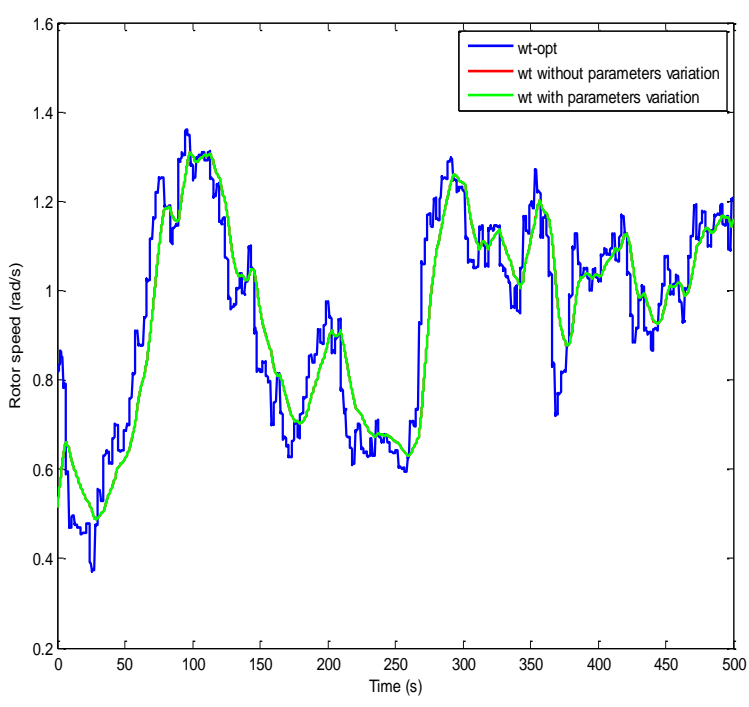

Fig. 17. Rotor Speed

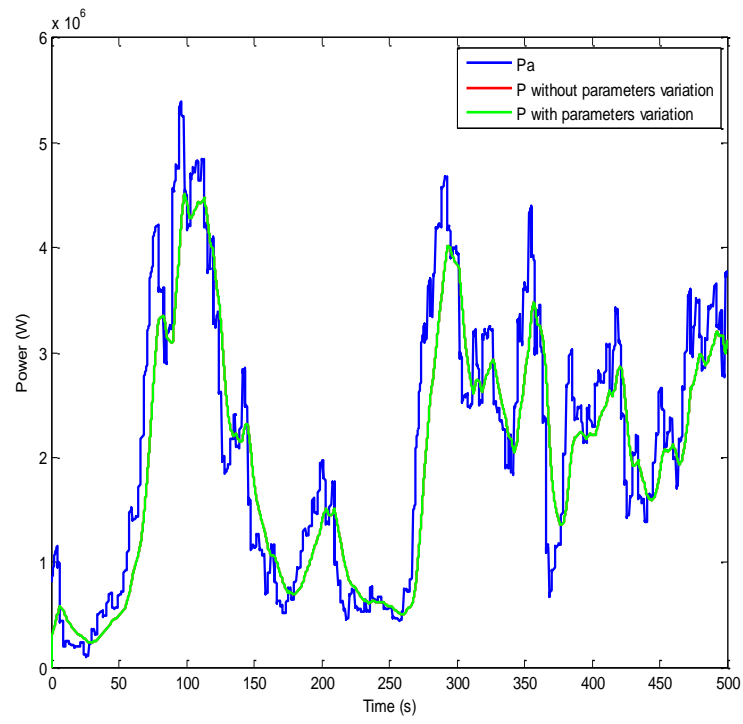

Fig. 18. Power Response.

\section{B. Comparison with PI Controller}

The obtained performance of both strategies controllers are shown in Fig. 19, 20 and 21. The selected comparison criteria are the maximum electromagnetic torque, the standard deviation of $T_{e m}$, the maximum power capture and the power efficiency. The simulation results verify that the IMC controller design and the conventional PI controller have the same behaviour. It can be seen from the Table II that the PMSG vector control which made up of two inner-current loops control based on PI action controllers is less effective than the control through the proposed IMC controller. So the IMC method has favourable response robustness and good control effect.

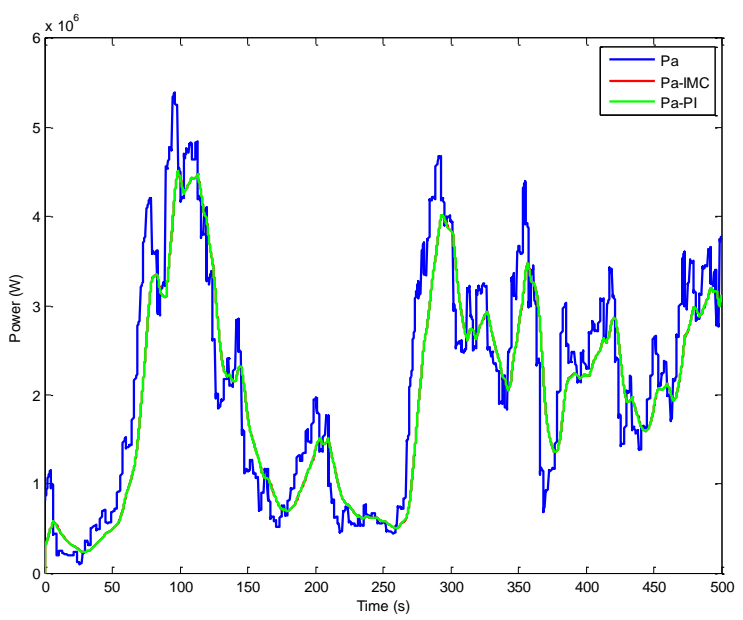

Fig. 19. Comparison of the Power Produced.

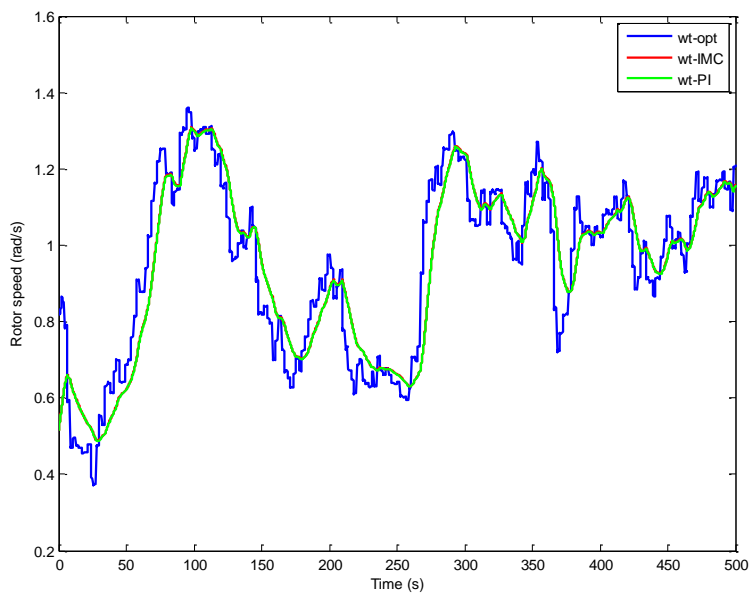

Fig. 20. Comparison of the Rotor Speed Response.

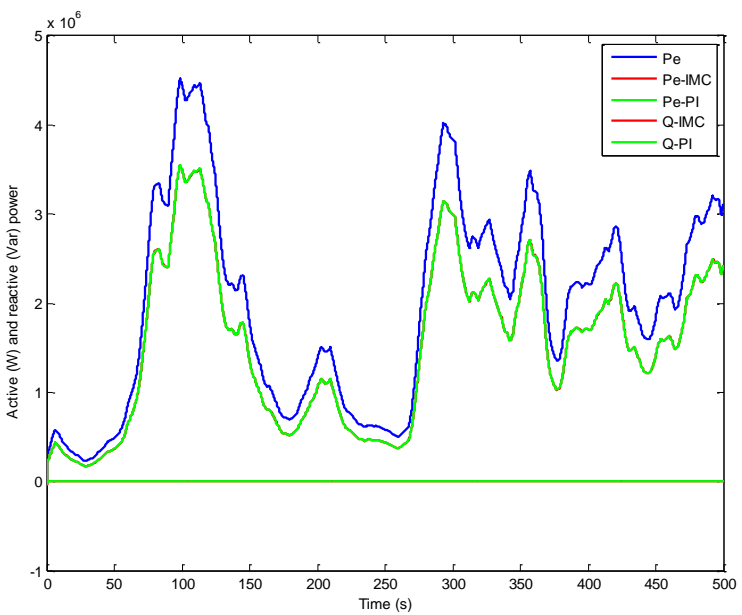

Fig. 21. Comparison of the Active and Reactive Power. 
TABLE II. COMPARISON OF THE TWO CONTROLLERS

\begin{tabular}{|l|l|l|}
\hline Controller & PI controller & IMC controller \\
\hline Maximum power (MW) & 4.5150 & 4.5169 \\
\hline Maximum torque (kN.m) & 37.686 & 37.629 \\
\hline Std (Tem) (kN.m) & 8.5897 & 8.6149 \\
\hline Efficiency \% & 82.9 & 83.7 \\
\hline
\end{tabular}

\section{CONCLUSION}

This paper has dealt with variable speed PMSG wind turbine in order to achieve the objective of maximizing the power energy extract from the wind. Two control strategies are applied to the PMSG: the conventional PI controller and the proposed Internal Model Controller design. The regulating of the generator speed has been provided by the maximum power point tracking. The IMC is applied to the current control to improve performance. The $\mathrm{d}-\mathrm{q}$ axis currents have been successfully decoupled by the designed control strategy and both of them can follow the reference accurately. The proposed technique is suitable for variable speed wind generation system and ensures the best performance in term of efficiency.

The proposed control design has the advantages of set-point tracking controller and disturbance rejection performances. The simulation results demonstrate the effectiveness and the robustness of the proposed method.

As future research, it needs to take account to the nonlinearity of the power coefficient and integrate a nonlinear controller design for PMSG variable speed wind turbine. Additionally, it is interest to enhance the current study with active and reactive power control exchanged between PMSG and the electrical network during voltage drop.

\section{REFERENCES}

[1] Changliang Xia, Yan Yan, Peng Song, and Tingna Shi. "Voltage Disturbance Rejection for Matrix Converter-Based PMSM Drive System Using Internal Model Control" IEEE Transactions On Industrial Electronics, vol. 59, no. 1, January 2012.

[2] Wenchao Meng, Qinmin Yang, and Youxian Sun "Guaranteed Performance Control of DFIG Variable-Speed Wind Turbines" IEEE Transactions on Control Systems Technology Vol.24, pp 2215-2223, 2016.
[3] C.E.Garcia and M.Morari. "Internal Model control-1: a unifying review and some new results." Industrial Engineering Chemistry Process Design and Development, Vol.21, No 2, pp 308-323, 1982.

[4] C.E.Garcia and M.Morari. "Internal Model control-2: design procedure for multivariable systems." Industrial Engineering Chemistry Process Design and Development, Vol.24,No 3, pp 427-484, 1985.

[5] A. Gift IssacA A , P. K. Senthil Kumara. "Fuzzy Adaptive Internal Model control for the speed regulation of a Permanent Magnet Synchronous motor with an Index matrix converter." International Journal of Current Engineering and Technology, 2014.

[6] Abdullah M.A. , Yatim A.H.M., Tan C.W., Saidur R. "A review of maximum power point tracking algorithms for wind energy systems." Renewable and Sustainable Energy Reviews 16, pp 3220-3227, 2012.

[7] Guohai Liu, Lingling Chen, Wenxiang Zhao, Yan Jiang, Li Qu. "Internal Model Control of Permanent Magnet Synchronous Motor Using Support Vector Machine Generalized Inverse.” IEE Transactions On Industrial Informatics, Vol.9, No.2, May, 2013.

[8] Y.Erramia, M.Ouassaidb, M.Maaroufi "Optimal Power Control Strategy of Maximizing Wind Energy Tracking and different operating conditions for Permanent Magnet Synchronous Generator Wind Farm" Energy Procedia, Vol. 74, August, 2015.

[9] M.Benkahla, R.Taleb, Z.Boudjema "Comparative study of RobustControl Strategies for a DFIG-based Wind Turbine" IJACSA International Journal of Advanced Computer Science and Applications, Vol. 7, No.2, 2016.

[10] Hao Gu, Shihua Li. "Modified Internal Model Control of PMSM Speedregulation System" The International Federation of Automatic Control Milano, 2011.

[11] A.Dhahri, I.Saidi, D.Soudani "A New Internal Model Control Method for MIMO Over-Actuated Systems". IJACSA International Journal of Advanced Computer Science and Applications, Vol. 7, No.10, 2016.

[12] I.Saidi, A.Dhahri, D.Soudani "IMC Controllers for Uncertain Multivariable Over-Actuated Systems" the International Conference on Advanced Systems and Electric Technologies, pp 346-350, HammametTunisia, 2017.

[13] A.Hammami, I.Saidi, D.Soudani "Design of an Internal Model Control strategy for Grid side Converter for the Permanent Magnet Synchronous Generator" $5^{\text {th }}$ International Conference on Control and Signal Processing, Tunisia,Vol.26, pp 145-151, 2017.

[14] D.V.N.Ananth, G.V.Nagesh Kumar, P.V.S.Sobhan, P.Nageswara Rao and N.G.S.Raju. "Improved Internal Model Controller Design to Control Speed and Torque Surges for Wind Turbine Driven Permanent Magnet Synchronous Generator" IEEE Asia Pacific Conference on Postgraduate Research in Microelectronics and Electronics, 2013.

[15] Zaijun Wu, Xiaobo Dou, Jiawei Chu, Minqiang Hu "Operation and Control of a Direct-Driven PMSG-Based Wind Turbine System with an Auxiliary Parallel Grid-Side Converter."Energies, Vol 6, No.7, pp 34053421, 2013. 